\title{
Acute respiratory muscle weakness and apnea in a critically ill patient induced by colistin neurotoxicity: key potential role of hemoadsorption elimination during continuous venovenous hemofiltration
}

This article was published in the following Dove Press journal: International Journal of Nephrology and Renovascular Disease 6 June 2013

Number of times this article has been viewed

\author{
Patrick M Honore' \\ Rita Jacobs' \\ Stijn Lochy' \\ Elisabeth De Waele' \\ Viola Van Gorp' \\ Jouke De Regt' \\ Geert Martens' \\ Olivier Joannes-Boyau ${ }^{2}$ \\ Willem Boer ${ }^{3}$ \\ Herbert D Spapen' \\ 'Universitair Ziekenhuis Brussel, Vrije \\ Universiteit Brussel, Brussels, Belgium; \\ ${ }^{2}$ Haut Leveque University Hospital of \\ Bordeaux, University of Bordeaux 2, \\ Pessac, France; ${ }^{3}$ Ziekenhuis Oost- \\ Limburg, Genk, Belgium
}

Correspondence: Patrick M Honore Intensive Care Department, Universiteit Ziekenhuis Brussel, Vrije Universiteit Brussels, Laarbeeklaan I0I,

B- 1090 Brussels, Belgium

Tel +32 24775178

Fax +32 24775179

Email patrick.honore@uzbrussel.be

\begin{abstract}
We describe a patient with severe New Delhi metallo- $\beta$-lactamase-1 Escherichia coli infection who developed convulsions rapidly followed by acute respiratory muscle weakness and apnea while receiving intravenous colistin. Toxic levels of colistin were rapidly removed by hemofiltration and, more specifically, by hemoadsorption.
\end{abstract}

Keywords: colistin, neurotoxicity, convulsions, neuromuscular blockade, apnea, hemofiltration, hemoadsorption, CVVH, CRRT

\section{Case report}

A 51-year-old Pakistani man presented to the emergency department with a painfully swollen right lower limb. His medical history revealed insulin-dependent diabetes mellitus and a recent hospitalization in Pakistan with a crush trauma of the right foot. Apparently, the patient had left the hospital without specific treatment and had flown directly to Belgium.

On admission, his blood pressure was $130 / 88 \mathrm{mmHg}$, heart rate 105 beats/minute, respiratory rate 26 breaths/minute, tympanic temperature $35.5^{\circ} \mathrm{C}$, and oxygen saturation $98 \%$. His body weight was $80 \mathrm{~kg}$. Relevant laboratory results were as follows: C-reactive protein $348 \mathrm{mg} / \mathrm{L}$ (normal $<5$ ), white blood cell count $28.4 \times 10^{3}$ cells $/ \mathrm{mm}^{3}$ with $88.5 \%$ neutrophils and $>10 \%$ band forms, urea $276 \mathrm{mg} / \mathrm{dL}$, and creatinine $2.39 \mathrm{mg} / \mathrm{dL}$. An arterial blood gas without supplemental oxygen showed $\mathrm{pH} 7.49$, partial pressure of carbon dioxide in the blood $26 \mathrm{mmHg}$, partial pressure of oxygen in the blood $98 \mathrm{mmHg}$, base excess $-3 \mathrm{mEq} / \mathrm{L}$, and a lactate level of $2.4 \mathrm{mmol} / \mathrm{L}$. Physical examination was unremarkable except for extensive right foot necrosis with fetid purulent discharge and lymphadenitis. Right lower leg amputation was performed and the patient was transferred postoperatively to the intensive care unit (ICU). Antibiotic treatment at that time consisted of ciprofloxacin (400 mg every 8 hours [q8h]) and clindamycin (600 mg q8h). Wound cultures grew methicillin-resistant Staphylococcus aureus, $\beta$-hemolytic streptococcus, Bacteroides fragilis, Morganella morganii, and New Delhi metallo- $\beta$-lactamase-1 Escherichia coli. The latter was susceptible only to colistin (minimum inhibitory concentration [MIC] $0.125 \mu \mathrm{g} / \mathrm{mL}$ ) and tigecycline (MIC $0.5 \mu \mathrm{g} /$ $\mathrm{mL})$. Therapy was changed to meropenem ( $1 \mathrm{~g} \mathrm{q} 8 \mathrm{~h}$ ), vancomycin (continuous infusion 
over 24 hours, target plateau concentration $25-30 \mu \mathrm{g} / \mathrm{mL}$ ), and colistin (3 million units [MIU] q8h).

Due to insufficiently controlled infection of the amputation stump, sepsis persisted and on day 4 after admission the right upper limb was amputated. Tigecyclin (100 mg loading, followed by $50 \mathrm{mg} \mathrm{q} 12 \mathrm{~h}$ ) was added to the antibiotic regimen. The patient recovered well after surgery. Inflammatory parameters decreased and plasma creatinine reached stable levels (Figure 1). Antibiotic treatment was continued, and intensive local wound control with daily local debridement was provided.

On day 15, surgical site infection and sepsis recurred, necessitating broad wound surgical debridement under general anesthesia. Antibiotics were left unchanged except for a dose reduction of meropenem ( $2 \mathrm{~g} \mathrm{q12h}$ ) because of a slight postoperative plasma creatinine increase (Figure 1). In the late afternoon of day 18 , the patient suddenly presented generalized convulsions. A brain computed tomography scan was normal. Lumbar puncture yielded crystal-clear cerebrospinal fluid with normal cellular, protein, and glucose content. No benzodiazepine was used to break seizure. Colistin was withdrawn and levetiracetam given intravenously. The patient experienced increasing difficulty breathing and suddenly developed apnea, necessitating urgent endotracheal intubation. The plasma level of colistin base at that time was $8.06 \mu \mathrm{g} / \mathrm{mL}$. Although highly probable, the diagnosis of apnea upon colistin intoxication cannot be definitively confirmed. Continuous venovenous hemofiltration (CVVH) was set up with an AN69 ST (surface treated) membrane known as a very adsorptive filter (Gambro, Lund, Sweden). CVVH was done exclusively in a hemofiltration mode at a dose of $35 \mathrm{~mL} / \mathrm{kg} / \mathrm{h}$ (GambroPrismaflex, Lund, Sweden). Blood flow was set at $200 \mathrm{~mL} /$ min, and predilution and postdilution were, respectively, $65 \%$ and $35 \%$. Citrate anticoagulation was used without any side effects. The surface area was $1.5 \mathrm{~m}^{2}$. Colistin concentrations in plasma and ultrafiltrate were determined simultaneously before the start of CVVH and at 1, 3, 5, 7, 11 , and 15 hours thereafter. The initial plasma colistin concentration of $8.06 \mu \mathrm{g} / \mathrm{mL}$ (peak level) fell within 12 hours to below $1 \mu \mathrm{g} / \mathrm{mL}$ (Figure 2, dotted line). The maximal colistin concentration $(0.46 \mu \mathrm{g} / \mathrm{mL})$ in the ultrafiltrate was attained only after 3 hours (Figure 2, plain line). The patient continued to deteriorate hemodynamically and finally succumbed to intractable septic shock. The patient was completely anuric at this time, and thus colistin could be eliminated only by CVVH.

\section{Discussion}

Colistin is a polypeptide antibiotic composed mainly of polymyxin $\mathrm{E}_{1}$ and $\mathrm{E}_{2}$. It is administered parenterally as the prodrug colistimethate sodium, a fraction of which is hydrolyzed

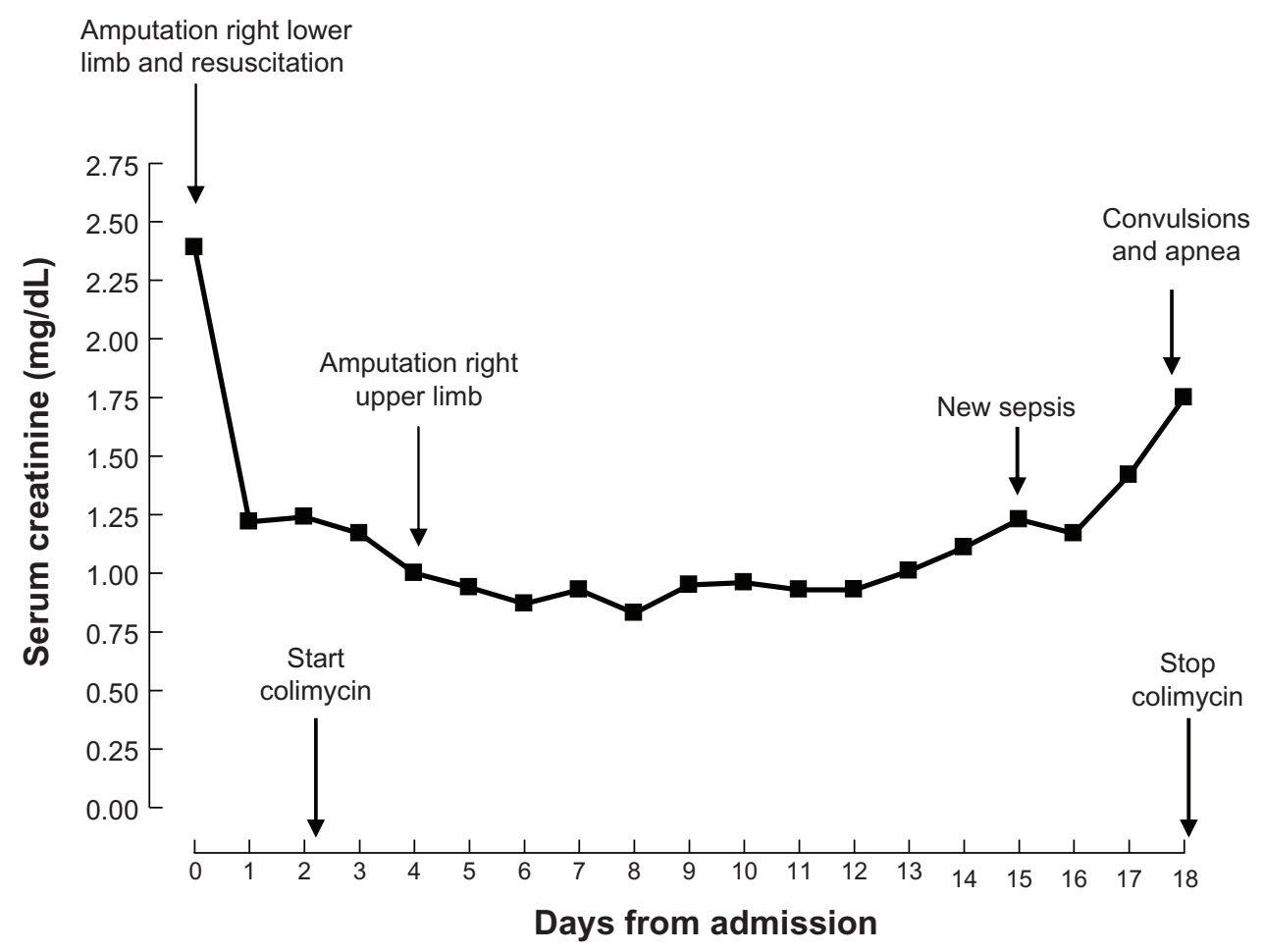

Figure I Evolution of serum creatinine in relation to important clinical events and colimycin treatment. 


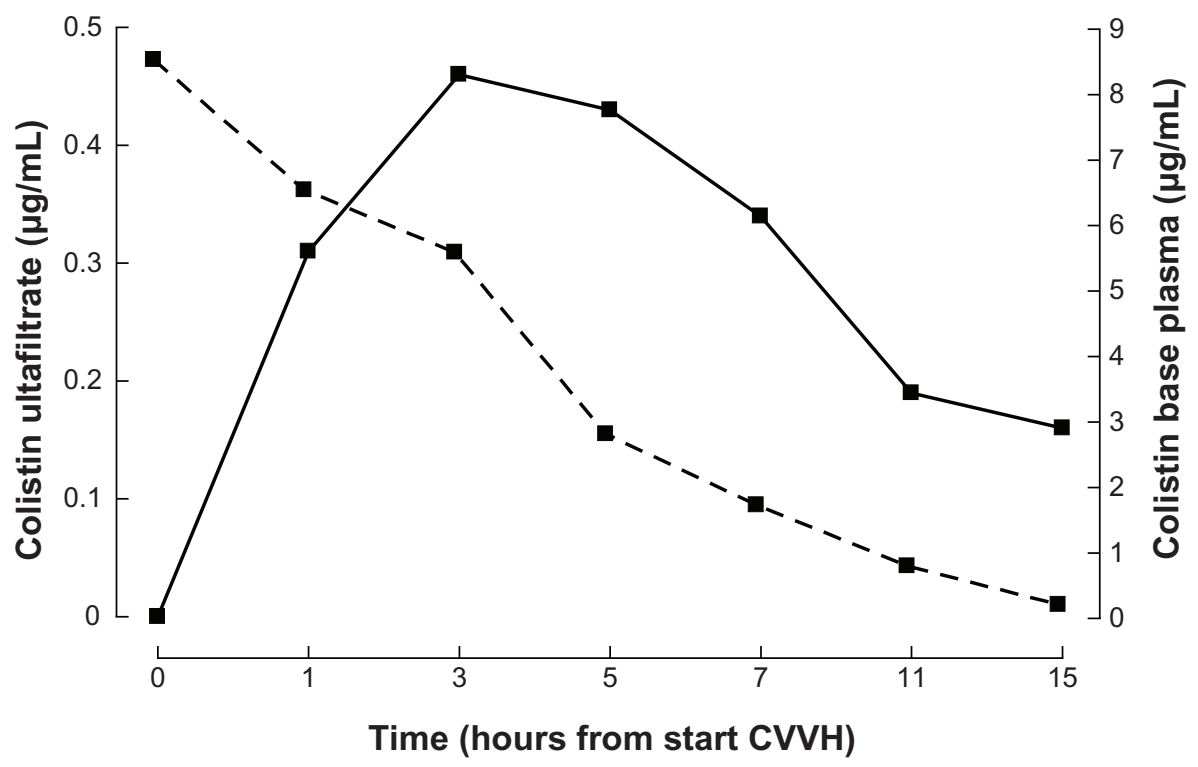

Figure 2 Colistin base concentrations in plasma and ultrafiltrate during continuous venovenous hemofiltration $(\mathrm{CVVH})$. Notes: Ultrafiltrate: plain line; Plasma: dotted line.

in vivo to colistin. Colistin causes rapid bacterial killing in a concentration-dependent manner. Following intravenous administration, the drug is mainly renally excreted, with $40 \%$ of the dose recovered in the urine within 8 hours. Colistin use has always been hampered by the occurrence of renal toxicity and, to a lesser extent, neurological adverse effects. New and less toxic antibiotics with a comparable or broader antibacterial spectrum progressively supplanted colistin during the 1970s. However, the mounting prevalence worldwide of infections due to multidrug-resistant Gram-negative bacilli has renewed interest in this antimicrobial but has also revived the discussion about its toxicity. ${ }^{1}$

The interaction of colistin with neurons that have a high lipid content has been associated with neurotoxicity, including peripheral, oral, and facial paresthesias, vertigo, visual disturbances, hallucinations, mental confusion, ataxia, and seizures. The most dreaded neurotoxic event, however, is neuromuscular blockade presenting either as a myasthenialike syndrome or as respiratory muscle paralysis producing apnea. Potential triggers of neurotoxicity are hypoxia, impaired renal function, and concomitant medication (muscle relaxants, narcotics, sedatives, anesthetic drugs, and corticosteroids). ${ }^{2}$ The incidence of colistin-associated neurotoxicity reported in the literature before 1975 was approximately $7 \%$, with paresthesias constituting the main event. Only sporadic cases of apnea were reported, typically in patients receiving colistin intramuscularly, suffering either acute or chronic renal failure, or treated with medications known to potentially induce respiratory muscle weakness. ${ }^{2}$
More recent studies - all retrospective in design - did not observe a clear association between colistin treatment and neurotoxic events. Falagas et $\mathrm{al}^{3}$ described four patients who presented with polymyoneuropathy during colistin treatment. However, three patients already had neurological symptoms before colistin was started, and in the one remaining patient polyneuropathic symptoms subsided, although colistin was continued for 11 more days. Sabuda et $\mathrm{al}^{4}$ reported four subjects with varying neurological complaints. All had developed significant renal dysfunction during treatment. Two patients had either concomitant neurotoxic medication (gabapentin, baclofen, and tizanidine) or disorders (multifocal acute encephalopathy) that might have contributed to their neurological "distress" (respectively somnolence and vertigo). One patient with respiratory muscle weakness had received the equivalent of $13 \mathrm{MIU}$ of colistin base per day for 19 days whilst experiencing a doubling of plasma creatinine levels. In a cohort of 115 patients, Cheng et $\mathrm{al}^{5}$ identified four cases of potential colistin-induced neurotoxicity, including three patients with focal seizures and one patient with altered mental status. These patients had normal kidney function, but details about concomitant treatment or comorbidities were not given. Of note, no clinically significant neurotoxicity was observed during colistin treatment in a large group of patients with underlying neurological disorders admitted to a neurosurgical ICU. ${ }^{6}$ Except for one (not so well documented) case of diffuse muscular weakness in an ICU patient that spontaneously resolved 1 month after discharge, neuromuscular toxicity has never been described in prospective studies 
evaluating colistin treatment. ${ }^{2}$ Diagnosis of neurotoxicity is mostly made on clinical grounds, making it difficult to discriminate eventual colistin-induced neurotoxicity from the more frequently observed "critical illness polymyoneuropathy" in ICU patients. In only one study, electrophysiological measurement was performed in a limited number of patients who had received colistin for at least 7 days. Among these patients, 50\% exhibited typical features consistent with critical illness polymyoneuropathy, but none had evidence of neuromuscular junction blockade. ${ }^{7}$

The sudden occurrence of respiratory muscle weakness and apnea in our patient was unexpected. He received intensive respiratory and muscle reinforcement physiotherapy daily and never complained of any neuromuscular discomfort. Sedatives, strong analgesics, steroids, or muscle relaxants were not administered. Tigecyclin and vancomycin have no known neurotoxic side effects. Carbapenems can produce neurotoxicity. ${ }^{8}$ However, carbapenem-induced neuromuscular blockade has never been described. Meropenem has the lowest neurotoxic potential of all carbapenems, and its dose was appropriately adapted to renal function.

One could argue that the patient received an excessive dose of colistin. Product information $\left(\right.$ Colistineb $^{\circledR}$, Forest Laboratories, Kent, UK) recommends a dose of 1-2 MIU q8h in adults weighing more than $60 \mathrm{~kg}$, which is, indeed, lower than the prescribed dose in our patient. However, during the last 2 years of a 7-year cohort study evaluating 258 patients of whom $86 \%$ were hospitalized in the ICU, colistin dose was standardized to $9 \mathrm{MIU} /$ day. ${ }^{9}$ No significant neurotoxicity was observed even when treatment was given for more than 4 weeks. ${ }^{4}$ Sparse pharmacokinetic and pharmacodynamic data in critically ill patients demonstrated maximum mean steady state concentrations of colistin base between 2.3 and $3.9 \mu \mathrm{g} / \mathrm{mL}$ after administration of $3 \mathrm{MIU}$ q $8 \mathrm{~h} .{ }^{10,11}$ The colistin base concentration measured at occurrence of neuromuscular blockade in our patient, though largely exceeding the MIC value for the culprit Escherichia coli, would still be considered suboptimal for treatment of Pseudomonas aeruginosa and Acinetobacter baumannii strains currently reported as sensitive (MIC $\leq 2 \mu \mathrm{g} / \mathrm{mL}$ ). Finally, $70 \%$ of patients with cystic fibrosis receiving the equivalent of $13.5-18.5 \mathrm{mg} / \mathrm{kg} /$ day of colistimethate sodium for up to 35 days (compared with our patient receiving $9 \mathrm{mg} / \mathrm{kg} /$ day for 17 days) experienced paresthesias, headache, and lower limb weakness but never developed neuromuscular blockade. ${ }^{12}$

The late deterioration of renal function might have elicited neurotoxicity. However, this is difficult to anticipate. Plasma levels of colistin are not routinely measured and are not correlated with creatinine clearance values. ${ }^{10}$ Also, a relationship between a given plasma level and the appearance of severe neurotoxic events has never been described. Product information suggests maintaining the amount of each colistin dose without extending the dosing interval when creatinine clearance is maintained between 20 and $50 \mathrm{~mL} / \mathrm{min}$. Calculated creatinine clearance during treatment in our patient never decreased below $40 \mathrm{~mL} / \mathrm{min}$.

Colistin-induced neurological symptoms are mostly not evident and usually do not necessitate treatment modification. If more serious neurotoxicity is suspected, the antibiotic should be withdrawn. Colistin is also eliminated by intermittent or, as shown in our patient, continuous hemofiltration using the CVVH modality. Intermittent hemodialysis (IHD) rapidly removed "normal" colistin levels of around $2 \mu \mathrm{g} / \mathrm{mL} .{ }^{13}$ However, no data exist on the ability of IHD to efficiently remove potentially severe toxic levels of colistin exceeding $8 \mu \mathrm{g} / \mathrm{mL}$. CVVH was used in our patient because of hemodynamic instability and to avoid any rebound effect of colistin as might occur with IHD. We did not calculate the clearance of colistin. Indeed, this calculation was impossible, as an important fraction was eliminated by hemoadsorption. Moreover, by doing an indirect measure of the area under the curve (Figure 2, dotted line), hemoadsorption was responsible for probably more than $80 \%$ of the elimination until membrane saturation was reached. Still, colistin elimination from plasma was as effective as in the patients reported by Marchand et al. ${ }^{13}$ Our case, however, is very different from the one presented by $\mathrm{Li}$ et al. ${ }^{14}$ These authors used CVVH at a dose lower than $35 \mathrm{~mL} / \mathrm{kg} / \mathrm{h}$ (ie, $27 \mathrm{~mL} / \mathrm{kg} / \mathrm{h}$ with the associate dialysis), as well as a classical AN-69 membrane (Gambro) with less adsorptive properties than our AN69 ST membrane. The maximal concentration of colistin in the effluent was reached only after 3 hours of CVVH in our patient. If convection was the sole way of eliminating colistin, then concentrations in the effluent should completely mirror plasma concentrations. The "delayed" elimination can be explained only by adsorption. Colistin removal by convection alone would indeed have been greater, as initial plasma levels were high, thereby producing higher colistin levels in the effluent. As this was not observed during the first hours of CVVH in our patient, colistin must be largely adsorbed in the membrane. With saturation occurring after 3 hours, ultrafiltrate concentrations subsequently became proportional to those in plasma. Adsorption is still an important mechanism of removal in $\mathrm{CVVH} .{ }^{15} \mathrm{~A}$ careful look at the graph accompanying the case reported by $\mathrm{Li}$ et $\mathrm{al}^{14}$ shows a similar pattern of removal, though less pronounced, as the used membrane 
was less adsorptive. To our knowledge, our case is the first description of colistin adsorption while employing CVVH with a highly adsorptive membrane. This finding may offer important perspectives with regard to urgent treatment of life-threatening colistin toxicity in hemodynamically unstable critically ill patients. According to the reports of $\mathrm{Li}$ et al ${ }^{14}$ and our findings, adsorption is the main mechanism of removal of colistin and might be responsible for $80 \%$ of the whole removal.

In conclusion, a case of colistin-associated neuromuscular blockade presenting as sudden severe respiratory muscle weakness and apnea is described. The rising incidence of multidrug-resistant Gram-negative infections in the critically ill will probably produce an increase in colistin prescriptions. Moreover, recent clinical and pharmacological experience supports the use of a higher than currently prescribed colistin dose. Therefore, it is of utmost importance that clinicians remain aware of this rare but life-threatening complication when prescribing colistin. CVVH at a dose of $35 \mathrm{~mL} / \mathrm{kg} / \mathrm{h}$ and using a highly adsorptive membrane might be an excellent tool for rapid and adequate elimination of colistin, avoiding any rebound effect.

\section{Disclosure}

The authors declare that they have no competing interests.

\section{References}

1. Li J, Nation RL, Turnidge JD, Milne RW, Coulthard K, Rayner CR, et al. Colistin: the re-emerging antibiotic for multidrug-resistant Gramnegative bacterial infections. Lancet Infect Dis. 2006;6:589-601.

2. Falagas ME, Kasiakou SK. Toxicity of polymyxins: a systematic review of the evidence from old and recent studies. Crit Care. 2006;10:R27.

3. Falagas ME, Rizos M, Bliziotis JA, Rellos K, Kasiakou SK, Michalopoulos A. Toxicity after prolonged (more than four weeks) administration of intravenous colistin. BMC Infectious Diseases. 2005;5:1.

4. Sabuda D, Laupland K, Pitout J, Dalton B, Rabin H, Louie T, et al. Utilization of colistin for treatment of multidrug-resistant Pseudomonas aeruginosa. Can J Infect Dis Med Microbiol. 2008;19:413-418.
5. Cheng C-Y, Sheng W-H, Wang J-T, Chen Y-C, Chang S-C. Safety and efficacy of intravenous colistin (colistin methanesulphonate) for severe multidrug-resistant Gram-negative bacterial infections. Int J Antimicrob Agents. 2010;35:297-300.

6. Koomanachai P, Tiengrim S, Kiratisin P, Thamlikitkul V. Efficacy and safety of colistin (colistimethate sodium) for therapy of infections caused by multidrug-resistant Pseudomonas aeruginosa and Acinetobacter baumanii in Siriraj Hospital, Bangkok, Thailand. Int J Infect Dis. 2007;11:402-406.

7. Garnacho-Montero J, Ortiz-Leyba C, Jiménez-Jiménez J, Barrero-Almodovar E, Garcia-Garmendia JL, Bernabeu-Wittell M, et al. Treatment of multidrug-resistant Acinetobacter baumanii ventilatorassociated pneumonia (VAP) with intravenous colistin: a comparison with imipenem-susceptible VAP. Clin Infect Dis. 2003;36:1111-1118.

8. Norrby SR. Neurotoxicity of carbapenem antibiotics: consequences for their use in bacterial meningitis. J Antimicrob Ther. 2000;45:5-7.

9. Falagas ME, Rafailidis PI, Ioannidou E, Alexiou VG, Matthaiou DK, Karageorgopoulos DE, et al. Colistin therapy for microbiologically documented multidrug-resistant Gram-negative bacterial infections: a retrospective cohort study of 258 patients. Int J Antimicrob Agents. 2010;35:194-199.

10. Markou N, Markantonis SL, Dimitrakis E, Panidis D, Boutzouka E, Karatzas $\mathrm{S}$, et al. Colistin serum concentrations after intravenous administration in critically ill patients with serious multidrug-resistant, Gram-negative bacilli infections: a prospective, open-label, uncontrolled study. Clin Ther. 2008;30:143-151.

11. Plachouras D, Karvanen M, Friberg LE, Papadomichelakis E, Antoniadou A, Tsangaris I, et al. Population pharmacokinetic analysis of colistin methanesulfonate and colistin after intravenous administration in critically ill patients with infections caused by Gram-negative bacteria. Antimicrob Agents Chemother. 2009;53:3430-3436.

12. Reed MD, Stern RC, O'Riordan MA, Blumer JL. The pharmacokinetics of colistin in patients with cystic fibrosis. J Clin Pharmacol. 2001;41: 645-654.

13. Marchand S, Frat J-P, Petitpas F, Lemaître F, Gobin P, Robert R, et al. Removal of colistin during intermittent haemodialysis in two critically ill patients. J Antimicrob Chemother. 2010;65:1836-1837.

14. Li J, Rayner CR, Nation RL, et al. Pharmacokinetics of colistin methanesulfonate and colistin in a critically ill patient receiving continuous veno-venous hemodiafiltration. Antimicrob Agents Chemother. 2005;49: 4814-4815.

15. Honore PM, Joannes-Boyau O, Boer W, Collin V, Jennes S. Continuous haemofiltration in 2009: what is new for clinicians regarding pathophysiology, preferred technique and recommended dose? Blood Purif. 2009;28:135-143.

\section{Publish your work in this journal}

The International Journal of Nephrology and Renovascular Disease is an international, peer-reviewed open-access journal focusing on the pathophysiology of the kidney and vascular supply. Epidemiology, screening, diagnosis, and treatment interventions are covered as well as basic science, biochemical and immunological studies. The journal welcomes
Dovepress

original research, clinical studies, reviews \& evaluations, expert opinion and commentary, case reports and extended reports. The manuscript management system is completely online and includes a very quick and fair peerreview system, which is all easy to use. Visit http://www.dovepress.com/ testimonials.php to read real quotes from published authors. 